\title{
The Role of Socioeconomic Status in the Association of Lung Function and Air Pollution-A Pooled Analysis of Three Adult ESCAPE Cohorts
}

\author{
Dirk Keidel $^{1,2, *(D)}$, Josep Maria Anto ${ }^{3,4,5,6}$, Xavier Basagaña ${ }^{3,5,6}$, Roberto Bono ${ }^{7}$, \\ Emilie Burte $3,5,8,9$, Anne-Elie Carsin $3,5,6$, Bertil Forsberg 10 (D), Elaine Fuertes ${ }^{11}$ (D), \\ Bruna Galobardes ${ }^{12}$, Joachim Heinrich ${ }^{13,14}$, Kees de Hoogh 1,2, Debbie Jarvis 11,15, \\ Nino Künzli ${ }^{1,2}$, Bénédicte Leynaert ${ }^{16}$, Alessandro Marcon ${ }^{17}$ (D) , Nicole Le Moual ${ }^{8,9}$, \\ Audrey de Nazelle ${ }^{18}$, Christian Schindler ${ }^{1,2}$, Valérie Siroux ${ }^{19}$, Morgane Stempfelet ${ }^{20}$, \\ Jordi Sunyer ${ }^{3,5,6}$, Sofia Temam ${ }^{8,9,20}$, Ming-Yi Tsai ${ }^{21}$, Raphaëlle Varraso ${ }^{8,9}$, \\ Bénédicte Jacquemin ${ }^{3,5,6,8,9}$ and Nicole Probst-Hensch 1,2
}

1 Swiss Tropical and Public Health Institute, 4051 Basel, Switzerland; c.dehoogh@swisstph.ch (K.d.H.); nino.kuenzli@swisstph.ch (N.K.); christian.schindler@swisstph.ch (C.S.); nicole.probst@swisstph.ch (N.P.-H.)

2 Department of Public Health, University of Basel, 4001 Basel, Switzerland

3 ISGlobal, 08003 Barcelona, Spain; josepm.anto@isglobal.org (J.M.A.); xavier.basagana@isglobal.org (X.B.); emilie.burte@inserm.fr (E.B.); anneelie.carsin@isglobal.org (A.-E.C.); jordi.sunyer@isglobal.org (J.S.); benedicte.jacquemin@isglobal.org (B.J.)

4 Hospital del Mar Medical Research Institute, 08003 Barcelona, Spain

5 Department of Experimental and Health Sciences, Universitat Pompeu Fabra, 08002 Barcelona, Spain

6 CIBER Epidemiología y Salud Pública, 08005 Barcelona, Spain

7 Department of Public Health and Pediatrics, University of Turin, 10126 Turin, Italy; roberto.bono@unito.it

8 INSERM, U1168, VIMA: Aging and Chronic Diseases, Epidemiological and Public Health Approaches, 94807 Villejuif, France; nicole.lemoual@inserm.fr (N.L.M.); STEMAM@mgen.fr (S.T.);

raphaelle.varraso@inserm.fr (R.V.)

9 Univ Versailles St-Quentin-en-Yvelines, UMR-S 1168, 78180 Montigny le Bretonneux, France

10 Public Health and Clinical Medicine, Umea University, University Hospital, 90187 Umea, Sweden; bertil.forsberg@envmed.umu.se

11 National Heart and Lung Institute, Imperial College London, London SW3 6LY, UK; e.fuertes@imperial.ac.uk (E.F.); d.jarvis@imperial.ac.uk (D.J.)

12 School of Social and Community Medicine, University of Bristol, Bristol BS8 1QU, UK; bruna.galobardes@gmail.com

13 Institute of Epidemiology, German Research Center for Environmental Health (GmbH), Helmholtz Zentrum München, 85764 Neuherberg, Germany; heinrich@helmholtz-muenchen.de

14 Institute and Outpatient Clinic for Occupational, Social and Environmental Medicine, Ludwig Maximilians University, 80336 Munich, Germany

15 MRC-PHE Centre for Environment and Health, Imperial College London, London W2 1PG, UK

16 INSERM UMR1152, Physiopathologie et épidémiologie des Maladies Respiratoires, équipe Epidémiologie, 75018 Paris, France; benedicte.leynaert@inserm.fr

17 Unit of Epidemiology and Medical Statistics, Department of Diagnostics and Public Health, University of Verona, 37134 Verona, Italy; alessandro.marcon@univr.it

18 Centre for Environmental Policy, Imperial College London, Exhibition Road, South Kensington Campus, London SW7 2AZ, UK; anazelle@imperial.ac.uk

19 Institute for Advanced Biosciences, Inserm U1209, UMR CNRS 5309, Université Grenoble-Alpes, Team of Environmental Epidemiology Applied to Reproduction and Respiratory Health, 38700 Grenoble, France; valerie.siroux@ujf-grenoble.fr

20 InVS, French Institute for Public Health Surveillance, 94415 Saint-Maurice, France; Morgane.STEMPFELET@santepubliquefrance.fr

21 Department of Environmental and Occupational Health Sciences, University of Washington, Seattle, WA 98195, USA; mytsai2007@gmail.com

* Correspondence: dirk.keidel@swisstph.ch 


\begin{abstract}
Ambient air pollution is a leading environmental risk factor and its broad spectrum of adverse health effects includes a decrease in lung function. Socioeconomic status (SES) is known to be associated with both air pollution exposure and respiratory function. This study assesses the role of SES either as confounder or effect modifier of the association between ambient air pollution and lung function. Cross-sectional data from three European multicenter adult cohorts were pooled to assess factors associated with lung function, including annual means of home outdoor $\mathrm{NO}_{2}$. Pre-bronchodilator lung function was measured according to the ATS-criteria. Multiple mixed linear models with random intercepts for study areas were used. Three different factors (education, occupation and neighborhood unemployment rate) were considered to represent SES. $\mathrm{NO}_{2}$ exposure was negatively associated with lung function. Occupation and neighborhood unemployment rates were not associated with lung function. However, the inclusion of the SES-variable education improved the models and the air pollution-lung function associations got slightly stronger. $\mathrm{NO}_{2}$ associations with lung function were not substantially modified by SES-variables. In this multicenter European study we could show that SES plays a role as a confounder in the association of ambient $\mathrm{NO}_{2}$ exposure with lung function.
\end{abstract}

Keywords: Europe; socioeconomic position; air pollution; environmental equality; lung function

\title{
1. Introduction
}

Ambient air pollution is the biggest contributor to the total environmental burden of the disease [1,2]. $\mathrm{NO}_{2}$ is estimated to be responsible for 68,000 premature deaths and 723,000 YLL (years of life lost) in the European Union in 2013 [3].

It has previously been shown that both air pollution and single SES parameters can have independent adverse effects on lung function and that SES can modify the effect of poor air quality on respiratory health [4-8]. However, SES is a multidimensional phenomenon which cannot be fully captured by a single socioeconomic variable (e.g., education, occupation, income) [9]. The assessment of the independent and joint association of SES and air pollution with health is complicated by the fact that there's substantial variation in the relationship of air pollution exposure and individual SES in different cities and countries $[4,10]$. The role of socioeconomic and lifestyle factors as the confounder or effect modifier in the association between air pollution and health therefore remains a topic of great interest with regard to both causal inference and susceptibility related to air pollution health effects [11-13].

We investigated whether our previous ESCAPE (European Study of Cohorts for Air Pollution Effects) results on air pollution and lung function [14] were robust after the inclusion of further SES-variables. We then assessed whether SES influences the association between long-term exposure to traffic-related air pollution and respiratory function, using both individual-level (namely education and occupation) and neighborhood-level (unemployment rate) socioeconomic factors. This study uses pooled information from three adult respiratory cohorts which previously contributed data to the ESCAPE meta-analysis on air pollution and lung function [14] and the SESAP (Socioeconomic Status and Air Pollution in three European cohorts) pooled analysis on air pollution and SES [10]. In comparison to the first study [14], we additionally adjusted for the lifestyle variable pack-years of smoking and the SES-variables occupation and unemployment rate. The latter study [10] described the association between SES and $\mathrm{NO}_{2}$-exposure without considering health outcomes. 


\section{Materials and Methods}

\subsection{Study Population}

This is a cross-sectional study of 6502 adults who participated in the first follow-up of three Western European studies. Two of those studies share harmonized study protocols-the ECRHS (European Community Respiratory Health Survey) $(n=3772)$ [15] and the jointly initiated Swiss Study on Air Pollution and Lung and Heart Diseases (SAPALDIA) $(n=1922)$ [16]. Combined with EGEA (Epidemiological Study on the Genetics and Environment of Asthma) $(n=808)$ [17], these cohorts represent 22 study centers from eight European countries. Briefly, in ECRHS, more than 18,000 young adults aged 20 to 44 were recruited with an oversampling of asthmatics across Europe in 1991-1993 (ECRHS I) and 10,364 participated in the first follow-up (ECRHS II) between 2000 and 2002. SAPALDIA is a Swiss-wide cohort study covering three language regions. In 1991, 9651 participants aged 18 to 60 were recruited for a detailed interview and health examination (SAPALDIA 1). At the first follow-up (SAPALDIA 2), conducted in 2001-2003, 8047 participants provided health information. EGEA is a French case control and family-based study with 2047 participants including a group of asthmatic patients with their first-degree relatives and a group of control subjects recruited in the early 1990s (EGEA1: 1991-1995). At the first follow-up (EGEA2) conducted between 2003 and 2007, 1601 cohort subjects answered a detailed questionnaire. Many, but not all, of the centers in these three cohorts participated in the ESCAPE study [14]. In ESCAPE, harmonized air pollution measurement and modeling protocols were applied to estimate long-term exposure at the residential address of participants in the first study follow-up. The sample for the current analysis included participants who took part in the first follow-up of the three studies and who underwent lung function testing. The participants were from 20 urban areas in eight Western European countries, geographically spread across the North: Umea (Sweden), the central part: Ipswich, Norwich (United Kingdom); Erfurt (Germany); Antwerp (Belgium); Paris, Grenoble, Lyon (France); Geneva, Basel, Lugano (Switzerland) and the South of Europe: Marseille (France); Pavia, Turin, Verona (Italy); Albacete, Barcelona, Galdakao, Huelva, Oviedo (Spain). Paris and Grenoble hosted centers for both ECRHS and EGEA. Since participants of the same town but from different studies differed substantially according to air pollution exposure and SES variables the study areas were split into Paris (ECRHS), Paris (EGEA), Grenoble (ECRHS), and Grenoble (EGEA). This resulted in the final number of 22 study areas.

\subsection{Air Pollution Exposure}

The current study focused on modeled annual average nitrogen dioxide $\left(\mathrm{NO}_{2}\right)$ at each participant's place of residence as a marker of traffic-related air pollution since this variable was available in all study areas. ESCAPE methods to estimate the $\mathrm{NO}_{2}$ annual concentrations are described in detail elsewhere [18]. Briefly, between 2008 and 2011, two-week integrated $\mathrm{NO}_{2}$ passive sampler measurements at approximately 40 sites in each study area were conducted in three different seasons over a one-year period. Area-specific land use regression (LUR) models were developed to explain the spatial variation of $\mathrm{NO}_{2}$ using a variety of geographical data including traffic, population and land use variables. The LUR models were applied to estimate $\mathrm{NO}_{2}$ annual concentrations at each participant's geocoded residential address at the first follow-up. The ESCAPE areas consist of small cities or metropolitan areas (larger cities with surrounding smaller suburban communities). The distribution of mean annual $\mathrm{NO}_{2}$ exposure by study area is presented in Figure 1. 


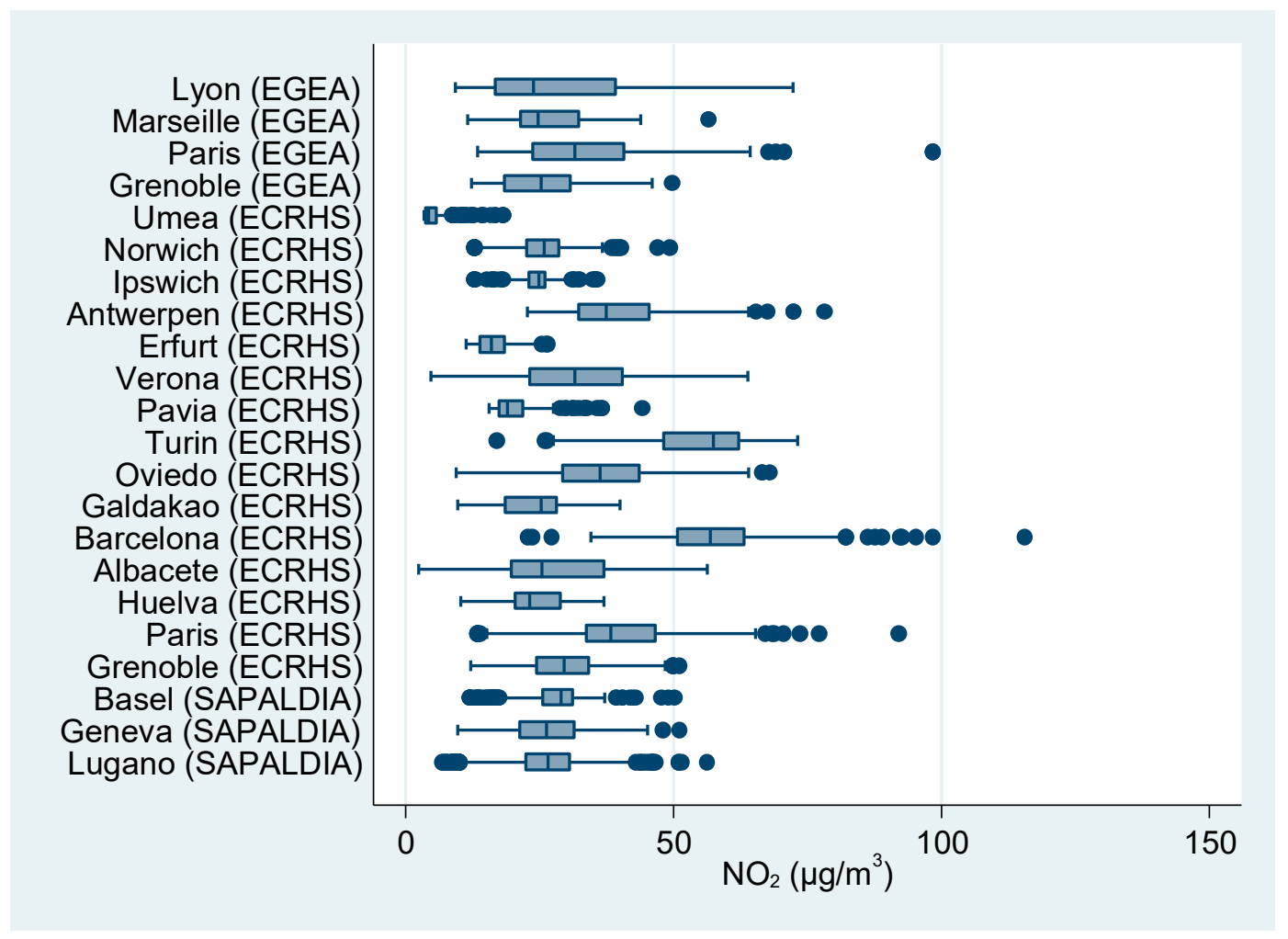

Figure 1. Boxplot of residential home outdoor nitrogen dioxide $\left(\mathrm{NO}_{2}\right)$ annual mean concentrations at first follow-up by cohort and study center (all three cohorts).

\subsection{Lung Function}

Lung function was assessed by spirometry according to ATS recommendations [19]. All measuring instruments (ECRHS: Water-sealed bell spirometer (Biomedin, Padova, Italy) in most centers; SAPALDIA: Sensormedics 2200 SP (SensorMedics Corporation, Yorba Linda, CA, USA) in all centers; EGEA: Biomedin or SPIRODYN'R in most centers (see online supplement of [14] for details) were calibrated prior to each testing session. The technical personnel were specifically trained. In all three studies pre-bronchodilator measurements were performed. The lung function parameters considered in the present analyses are FVC (forced vital capacity) and FEV1 (forced expiratory volume in $1 \mathrm{~s}$ ).

\subsection{Socioeconomic Factors}

Individual SES was categorized according to education and occupation. Education was defined as a three-level categorical variable according to ESCAPE definitions: For EGEA and SAPALDIA, the questions on the highest attained degree were used (low: Primary or secondary school; medium: Middle or apprenticeship school; high: Technical college or university) whereas for ECRHS, the age of completion of full-time education was subclassified into low ( $\leq 16$ years), medium (17-20 years) and high ( $\geq 21$ years). Occupation was categorized into manual compared to non-manual work by classifying the corresponding ISCO-88 codes [20] of the longest held job between the baseline and follow-up. The ISCO-88 major groups six (Skilled agricultural and fishery workers), seven (Craft and related trades workers), eight (Plant and machine operators and assemblers), and nine (Elementary occupations) were defined as manual work. Neighborhood level unemployment rate was available in a reduced sample of $n=4766$ subjects and $n=19$ study areas and was grouped into area-specific tertiles to allow better comparability in the analyses across countries. The exact definition of this neighborhood level variable is described elsewhere [10]. 


\subsection{Statistical Analysis}

All analyses are based on the pooled data from the three cohorts. We applied multiple mixed linear models to analyze the role of SES in the associations between $\mathrm{NO}_{2}$ and lung function and used the study area as a random intercept. Regarding SES, we included the following variables: Educational level (three categories), occupation (manual compared to non-manual), and the neighborhood-level variable tertile of unemployment rate. Models were adjusted for the basic variables sex, age, age squared, height, height squared and additionally for the lifestyle variables smoking status (i.e., current, former, or never smoker), pack-years and pack-years squared (each with separate terms for current and former smokers), BMI (body mass index), and BMI squared. We systematically ran analyses for the full sample $(n=6502)$ and for a reduced sample $(n=4766)$ since the unemployment rate was not available for three study areas. Likelihood-ratio (LR) tests and AIC (Akaike Information Criterion) were used to assess the contribution of SES factors to the models. Effect modification of SES on the association of lung function and $\mathrm{NO}_{2}$ were tested by including interactions terms in the models. We carried out the following sensitivity analyses: a) A meta-analysis comparing and combining study area-specific results to assess heterogeneity of associations between study sites, $b$ ) a three-level model using neighborhood level further nested within the study area, c) a three-level model taking the family structure of EGEA into account, and d) interaction analyses excluding the lifestyle variables (smoking status, pack-years and $\mathrm{BMI}$ ) to assess whether SES and $\mathrm{NO}_{2}$ interact when these possible mediator variables are excluded and thus might only be implicitly contained in SES. We used the statistical software Stata (StataCorp 2015. Stata Statistical Software: Release 14. StataCorp LP, College Station, TX, USA).

\section{Results}

Characteristics of the study population at the first follow-up are presented in Table 1 . The average age of participants was 46 years, and was highest in SAPALDIA. EGEA and SAPALDIA had slightly more female (52.8\% and $53.4 \%$, respectively) than male subjects. Nearly half $(47.6 \%)$ of the study participants were overweight or obese (i.e., had a BMI $>25 \mathrm{~kg} / \mathrm{m}^{2}$ ). On average, $30 \%$ of the subjects reported current smoking. Compared to the other two cohorts, there were fewer subjects in the low education group in SAPALDIA whereas subjects in EGEA had the highest proportion of high education. Manual work was most common in ECRHS (21.7\%). The median neighborhood level unemployment rate was $9.5 \%$. For further analyses this variable was grouped into study area-specific tertiles. Mean FVC and FEV1 were $4284 \mathrm{~mL}$ and $3368 \mathrm{~mL}$, respectively.

Table 1. Characteristics of the study population at the first follow-up.

\begin{tabular}{|c|c|c|c|c|c|}
\hline & & EGEA & ECRHS & SAPALDIA & Total \\
\hline Year & & 2003-2007 & $2000-2002$ & $2001-2003$ & \\
\hline $\mathrm{N}$ & & 808 & 3772 & 1922 & 6502 \\
\hline Age & & $44.9 \pm 16$ & $42.6 \pm 7.2$ & $52.7 \pm 11.4$ & $45.9 \pm 11$ \\
\hline Height $(\mathrm{cm})$ & & $168.4 \pm 8.7$ & $169 \pm 9.4$ & $168.7 \pm 9.2$ & $168.8 \pm 9.3$ \\
\hline $\mathrm{NO}_{2}\left(\mu \mathrm{g} / \mathrm{m}^{3}\right)$ & & $29 \pm 12.3$ & $29.6 \pm 15.7$ & $26.9 \pm 6.8$ & $28.7 \pm 13.3$ \\
\hline FVC (mL) & & $4172 \pm 1057$ & $4385 \pm 994$ & $4130 \pm 1028$ & $4284 \pm 1019$ \\
\hline FEV1 (mL) & & $3245 \pm 908$ & $3511 \pm 803$ & $3136 \pm 830$ & $3368 \pm 842$ \\
\hline Pack-years & & $0(0 ; 6.6)$ & $3.5(0 ; 18)$ & $2(0 ; 20)$ & $2.1(0 ; 17.3)$ \\
\hline Sex & Women & $52.8 \%$ & $48.7 \%$ & $53.4 \%$ & $50.6 \%$ \\
\hline BMI & $\begin{array}{l}\text { Underweight }(<18.5) \\
\text { Normal }(18.5-25) \\
\text { Overweight }(25-30) \\
\text { Obese }(>30)\end{array}$ & $\begin{array}{c}3.1 \% \\
58.4 \% \\
28.6 \% \\
9.9 \%\end{array}$ & $\begin{array}{c}1.6 \% \\
49.4 \% \\
35.6 \% \\
13.5 \%\end{array}$ & $\begin{array}{c}2.2 \% \\
49.0 \% \\
34.7 \% \\
14.2 \%\end{array}$ & $\begin{array}{c}2.0 \% \\
50.4 \% \\
34.4 \% \\
13.2 \%\end{array}$ \\
\hline
\end{tabular}


Table 1. Cont.

\begin{tabular}{|c|c|c|c|c|c|}
\hline & & EGEA & ECRHS & SAPALDIA & Total \\
\hline \multirow[t]{3}{*}{ Smoking } & Current & $21.5 \%$ & $32.2 \%$ & $28.0 \%$ & $29.6 \%$ \\
\hline & Former & $28.3 \%$ & $27.1 \%$ & $31.9 \%$ & $28.7 \%$ \\
\hline & Never & $50.1 \%$ & $40.6 \%$ & $40.1 \%$ & $41.7 \%$ \\
\hline \multirow[t]{3}{*}{ Education } & Low & $25.5 \%$ & $26.6 \%$ & $6.1 \%$ & $20.4 \%$ \\
\hline & Medium & $23.6 \%$ & $35.6 \%$ & $63.7 \%$ & $42.4 \%$ \\
\hline & High & $50.9 \%$ & $37.8 \%$ & $30.2 \%$ & $37.2 \%$ \\
\hline Occupation & manual & $9.7 \%$ & $21.7 \%$ & $16.5 \%$ & $18.7 \%$ \\
\hline \multicolumn{2}{|c|}{ Neighborhood unemployment rate $(\%)^{1}$} & $8.8(6.5 ; 11.3)$ & $10.9(6.8 ; 16)$ & $4.5(3.4 ; 5.3)$ & $9.5(5.8 ; 14.4)$ \\
\hline
\end{tabular}

High-educated subjects were more exposed to $\mathrm{NO}_{2}$ and low-educated subjects had the lowest lung function. Subjects in the manual workforce had lower $\mathrm{NO}_{2}$ exposure and a slightly higher lung function than people in non-manual jobs. For tertile of unemployment rate there was a positive association with $\mathrm{NO}_{2}$ and a weak negative association with lung function (Table 2).

Table 2. Unadjusted relations of socioeconomic status (SES)-variables with $\mathrm{NO}_{2}$ and lung function.

\begin{tabular}{llccc}
\hline & & $\mathbf{N O}_{\mathbf{2}}\left(\boldsymbol{\mu g} / \mathbf{m}^{\mathbf{3}}\right)$ & FVC $(\mathbf{m L})$ & FEV1 $(\mathbf{m L})$ \\
\hline Education & Low & $28.4 \pm 13.5$ & $4078 \pm 994$ & $3174 \pm 816$ \\
& Medium & $28.0 \pm 12.3$ & $4213 \pm 1016$ & $3300 \pm 842$ \\
& High & $29.8 \pm 14.1$ & $4478 \pm 1003$ & $3552 \pm 821$ \\
\hline Occupation & non-manual & $29.2 \pm 13.3$ & $4264 \pm 999$ & $3359 \pm 829$ \\
& Manual & $26.5 \pm 12.9$ & $4371 \pm 1099$ & $3409 \pm 895$ \\
\hline Neighborhood & Low & $27.1 \pm 14.3$ & $4393 \pm 1034$ & $3461 \pm 846$ \\
unemployment & Medium & $30.4 \pm 14.2$ & $4323 \pm 1024$ & $3421 \pm 837$ \\
rate tertile & High & $31.8 \pm 15.0$ & $4294 \pm 984$ & $3403 \pm 815$ \\
\hline
\end{tabular}

Presented are mean \pm standard deviation. $n=6502$ (education and occupation) and $n=4766$ (unemployment rate).

Unemployment rate was categorized into area-specific tertiles.

Associations between the SES-variables themselves are presented in Table 3. There is a strong relation between educational level and occupation, e.g., the proportion of subjects in the manual work force ranges from $4.3 \%$ for high education to $40.7 \%$ for low education. Subjects with low education or a manual occupation were the most likely to live in a neighborhood with an unemployment rate in the highest tertile.

Table 3. Cross-tabulation of SES-variables.

\begin{tabular}{|c|c|c|c|c|c|c|c|}
\hline & & & \multicolumn{3}{|c|}{ Tertiles of Unemployment Rate } & \multicolumn{2}{|c|}{ Occupation } \\
\hline & & & Low & Medium & High & Non-Manual & Manual \\
\hline \multirow[t]{6}{*}{ Educational level } & low & $\mathrm{N}$ & 355 & 407 & 481 & 737 & 506 \\
\hline & & $\%$ & $28.6 \%$ & $32.7 \%$ & $38.7 \%$ & $59.3 \%$ & $40.7 \%$ \\
\hline & medium & $\mathrm{N}$ & 539 & 520 & 531 & 1283 & 307 \\
\hline & & $\%$ & $33.9 \%$ & $32.7 \%$ & $33.4 \%$ & $80.7 \%$ & $19.3 \%$ \\
\hline & high & $\mathrm{N}$ & 715 & 666 & 552 & 1850 & 83 \\
\hline & & $\%$ & $37.0 \%$ & $34.5 \%$ & $28.6 \%$ & $95.7 \%$ & $4.3 \%$ \\
\hline \multirow[t]{4}{*}{ Occupation } & non-manual & $\mathrm{N}$ & 1365 & 1304 & 1201 & & \\
\hline & & $\%$ & $35.3 \%$ & $33.7 \%$ & $31.0 \%$ & & \\
\hline & manual & $\mathrm{N}$ & 244 & 289 & 363 & & \\
\hline & & $\%$ & $27.2 \%$ & $32.3 \%$ & $40.5 \%$ & & \\
\hline
\end{tabular}

Presented are n's and row percentages in the reduced sample $(n=4766)$. Pearson's Chi-squared-Test for all three cross-tables: $p<0.001$. 
Associations of $\mathrm{NO}_{2}$ with lung function from adjusted mixed linear models are presented in Table 4, both for the full and the reduced sample. Education was the only SES-variable that improved the model fit. We found rather strong evidence for associations between $\mathrm{NO}_{2}$ and the lung function in model M1 (basic and lifestyle variables), e.g., an adverse effect per $10 \mu \mathrm{g} / \mathrm{m}^{3}$ increment in $\mathrm{NO}_{2}$ in the full sample of $-15.8(-30.5 ;-1.2) \mathrm{mL}$ for FVC and $-11.3(-23.8 ; 1.2) \mathrm{mL}$ for FEV1. After including education in the models (Model M1 + education) the model fits improved and the estimates were stronger: $-17.2(-31.9 ;-2.6) \mathrm{mL}$ for FVC and $-12.7(-25.2 ;-0.3) \mathrm{mL}$ for FEV1. This corresponds with a $9 \%$ and $12 \%$ change in estimates for FVC and FEV1, respectively (e.g., by comparing the full sample estimates $-15.8 \mathrm{~mL}$ and $-17.2 \mathrm{~mL}$ for FVC) and is indicative of slight confounding by education. The models "Model M1 + education" have the lowest AIC for all combinations of the outcome and sample and are hence the best final models.

Table 4. Associations of lung function with $\mathrm{NO}_{2}$, results of adjusted mixed effect models.

\begin{tabular}{|c|c|c|c|c|c|c|}
\hline Outcome & Sample & Model & $\mathrm{NO}_{2}$ & $(95 \% \mathrm{CI})$ & $p$-Value & AIC \\
\hline FVC & Full & Basic and lifestyle variables (Model M1) & -15.8 & $(-30.5 ;-1.2)$ & 0.034 & $100,256.3$ \\
\hline FVC & Full & Model M1 + education & -17.2 & $(-31.9 ;-2.6)$ & 0.021 & $100,251.6$ \\
\hline FVC & Full & Model M1 + occupation & -15.9 & $(-30.6 ;-1.3)$ & 0.033 & $100,258.3$ \\
\hline FVC & Full & Model M1 + all SES-variables & -17.1 & $(-31.8 ;-2.4)$ & 0.022 & $100,253.2$ \\
\hline FVC & Reduced & Basic and lifestyle variables (Model M1) & -18.6 & $(-34.3 ;-2.9)$ & 0.02 & $73,571.5$ \\
\hline FVC & Reduced & Model M1 + education & -20.3 & $(-36 ;-4.6)$ & 0.011 & $73,568.4$ \\
\hline FVC & Reduced & Model M1 + occupation & -18.6 & $(-34.3 ;-2.9)$ & 0.021 & $73,573.5$ \\
\hline FVC & Reduced & Model M1 + education + occupation & -20.0 & $(-35.7 ;-4.2)$ & 0.013 & $73,569.4$ \\
\hline FVC & Reduced & Model M1 + unemployment tertile & -16.6 & $(-32.6 ;-0.7)$ & 0.041 & $73,573.9$ \\
\hline FVC & Reduced & Model M1 + all SES-variables & -18.2 & $(-34.3 ;-2.2)$ & 0.026 & $73,572.2$ \\
\hline FEV1 & Full & Basic and lifestyle variables (Model M1) & -11.3 & $(-23.8 ; 1.2)$ & 0.077 & $98,381.6$ \\
\hline FEV1 & Full & Model M1 + education & -12.7 & $(-25.2 ;-0.3)$ & 0.046 & $98,370.5$ \\
\hline FEV1 & Full & Model M1 + occupation & -11.7 & $(-24.2 ; 0.8)$ & 0.067 & $98,381.5$ \\
\hline FEV1 & Full & Model M1 + all SES-variables & -12.8 & $(-25.3 ;-0.3)$ & 0.045 & $98,372.4$ \\
\hline FEV1 & Reduced & Basic and lifestyle variables (Model M1) & -14.4 & $(-28 ;-0.8)$ & 0.038 & $72,427.9$ \\
\hline FEV1 & Reduced & Model M1 + education & -16.4 & $(-30 ;-2.8)$ & 0.018 & $72,418.1$ \\
\hline FEV1 & Reduced & Model M1 + occupation & -15.1 & $(-28.7 ;-1.5)$ & 0.03 & $72,427.6$ \\
\hline FEV1 & Reduced & Model M1 + education + occupation & -16.5 & $(-30.1 ;-2.9)$ & 0.017 & $72,420.0$ \\
\hline FEV1 & Reduced & Model M1 + unemployment tertile & -13.6 & $(-27.4 ; 0.3)$ & 0.054 & $72,431.5$ \\
\hline FEV1 & Reduced & Model M1 + all SES-variables & -16.2 & $(-30 ;-2.3)$ & 0.023 & $72,423.9$ \\
\hline
\end{tabular}

$\mathrm{n}=6502$ (full sample), $\mathrm{n}=4766$ (reduced sample with available unemployment rate). Each line shows results from one model. Results are presented in $\mathrm{mL}$ per $10 \mu \mathrm{g} / \mathrm{m}^{3} \mathrm{NO}_{2}$. Basic variables include sex, age, age squared, height and height squared. Lifestyle variables are smoking, pack-years, pack-years squared, interaction of smoking and pack-years, interaction of smoking and pack-years squared, body mass index (BMI), and BMI squared. Study center was included as a random intercept. A decrease in (akaike information criterion) AIC can be interpreted as an improvement of the model fit.

The parameter estimates for different education categories from the best models (i.e., Model M1 + education) are presented in Table 5 . Subjects with medium or high education had significantly higher lung function values than the reference category of low education: $47.9(7.3 ; 88.6) \mathrm{mL}$ for medium education and $62.3(20.6 ; 103.9) \mathrm{mL}$ for high education for FVC and $53.6(18.3 ; 88.9) \mathrm{mL}$ for medium education and 71.5 (35.3; 107.7) $\mathrm{mL}$ for high education for FEV1. Therefore, education had an independent effect on lung function and it also improved the model fit according to the LR-test (FVC: $p=0.0128$ and FEV1: $p=0.0005$, respectively). The positive association between education and lung function was also confirmed in the reduced sample (results not shown). 
Table 5. Independent association of education with lung function.

\begin{tabular}{cccccc}
\hline Outcome & SES & Group & Estimate $(\mathbf{m L})$ & $\mathbf{( 9 5 \%} \mathbf{C I})$ & $p$-Value \\
\hline FVC & Education & Low & - & reference & \\
FVC & & Medium & 47.9 & $(7.3 ; 88.6)$ & 0.021 \\
FVC & & High & 62.3 & $(20.6 ; 103.9)$ & 0.003 \\
\hline FEV1 & Education & Low & - & reference & \\
FEV1 & & Medium & 53.6 & $(18.3 ; 88.9)$ & 0.003 \\
FEV1 & & High & 71.5 & $(35.3 ; 107.7)$ & 0.000 \\
\hline
\end{tabular}

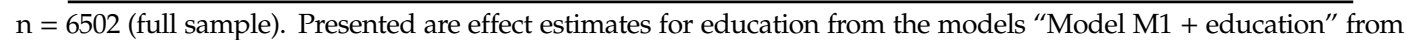
Table 4. Included in the models are the basic variables sex, age, age squared, height and height squared and additionally the lifestyle variables smoking, pack-years, pack-years squared, interaction of smoking and pack-years, interaction of smoking and pack-years squared, $\mathrm{BMI}$, and $\mathrm{BMI}$ squared, and $\mathrm{NO}_{2}$. Study center was included as a random intercept.

We tested interaction terms of $\mathrm{NO}_{2}$ with education for both the full and the reduced sample. According to the AIC and the LR-Test the inclusion of these interactions did not improve the models, neither for FVC nor FEV1 (Table 6). Still, when looking at results stratified by education categories there was a tendency for stronger air pollution effects with increasing educational level (Table 7). As SES itself is unlikely to have a causal effect on lung function we also tested the interaction of $\mathrm{NO}_{2}$ with education in models excluding the lifestyle variables BMI, smoking status, and pack-years. These variables might act as mediators of the effect of SES on lung function. There was also no evidence of effect modification by SES in the models unadjusted for lifestyle (results not shown).

Table 6. Assessment of interaction between $\mathrm{NO}_{2}$ and education on lung function.

\begin{tabular}{lllll}
\hline & Outcome & Sample & AIC & $p$-Value \\
\hline Model M1 + education & FVC & Full & $100,251.6$ & \\
Model M1 + education $+\mathrm{NO}_{2}{ }^{*}$ education & FVC & Full & $100,254.2$ & 0.49 \\
\hline Model M1 + education & FVC & Reduced & $73,568.4$ & \\
Model M1 + education $+\mathrm{NO}_{2}{ }^{*}$ education & FVC & Reduced & $73,569.8$ & 0.27 \\
\hline Model M1 + education & FEV1 & Full & $98,370.5$ & \\
Model M1 + education $+\mathrm{NO}_{2}{ }^{*}$ education & FEV1 & Full & $98,372.3$ & 0.34 \\
\hline Model M1 + education & FEV1 & Reduced & $72,418.1$ & \\
Model M1 + education $+\mathrm{NO}_{2}{ }^{*}$ education & FEV1 & Reduced & $72,418.8$ & 0.20 \\
\hline
\end{tabular}

For each of the two outcomes (forced vital capacity) FVC and (forced expiratory volume in $1 \mathrm{~s}$ ) FEV1 the interaction of $\mathrm{NO}_{2}$ and education was tested in both the full and the reduced sample. The first line lists AIC of the best model (M1 + education as presented in Table 4) and the second line gives the AIC and the p-value for the final model including the interaction. The $\mathrm{p}$-values are from likelihood-ration (LR)-Tests testing the interaction terms. A decrease in AIC can be interpreted as an improvement of the model fit.

As our data are from 22 study centers in eight European countries, we tested the heterogeneity of the main results across centers. We performed a random-effect meta-analysis of study area-specific models for the full sample. As we found only little evidence of heterogeneity we performed a fixed-effects meta-analysis, which resulted in comparable effect estimates of $-17.9(-32.8 ;-2.9) \mathrm{mL}$ change per $10 \mu \mathrm{g} / \mathrm{m}^{3} \mathrm{NO}_{2}$ for FVC and $-10.3(-23.4 ; 2.9)$ for FEV1, with no evidence of heterogeneity for FEV1 (Higgins $\mathrm{I}^{2}=0 \%$ ) and only weak evidence of heterogeneity for FVC ( $\mathrm{I}^{2}=24.5 \%$ ) (Supplement Figures S1 and S2). The three-level models with a) family (taking the family structure of EGEA into account) and b) neighborhood as a nested random factor within the study area showed very similar results as the main models (Supplement Table S1). 
Table 7. Adjusted association of $\mathrm{NO}_{2}$ with lung function, stratified by education.

\begin{tabular}{ccccccc}
\hline Outcome & Sample & SES & Group & Estimate & $\mathbf{( 9 5 \% ~ C I )}$ & $p$-Value \\
\hline FVC & full & education & low & -5.6 & $(-29.9 ; 18.7)$ & 0.653 \\
FVC & & & medium & -19.5 & $(-39.8 ; 0.7)$ & 0.059 \\
FVC & & & high & -22.0 & $(-41 ;-2.9)$ & 0.024 \\
\hline FVC & reduced & education & low & -8.3 & $(-33 ; 16.4)$ & 0.510 \\
FVC & & & medium & -16.8 & $(-39.1 ; 5.5)$ & 0.139 \\
FVC & & & high & -30.2 & $(-50.4 ;-10.1)$ & 0.003 \\
\hline FEV1 & \multirow{2}{*}{ full } & education & low & -0.5 & $(-21.5 ; 20.5)$ & 0.962 \\
FEV1 & & & medium & -14.5 & $(-31.9 ; 3)$ & 0.104 \\
FEV1 & & & high & -18.3 & $(-34.7 ;-1.9)$ & 0.028 \\
\hline FEV1 & reduced & education & low & -1.8 & $(-23.5 ; 19.8)$ & 0.868 \\
FEV1 & & & medium & -17.5 & $(-37 ; 1.9)$ & 0.077 \\
FEV1 & & & high & -24.7 & $(-42.3 ;-7.1)$ & 0.006 \\
\hline
\end{tabular}

$\mathrm{n}=6502$ (full sample). Results are presented in $\mathrm{mL}$ per $10 \mu \mathrm{g} / \mathrm{m}^{3} \mathrm{NO}_{2}$. Included in the models are the basic variables sex, age, age squared, height and height squared and additionally the lifestyle variables smoking, pack-years, pack-years squared, interaction of smoking and pack-years, interaction of smoking and pack-years squared, BMI, and BMI squared, and $\mathrm{NO}_{2}$. Study center was included as a random intercept.

\section{Discussion}

In this pooled analysis of data from a subset of ESCAPE cohorts we confirmed that the previously reported inverse cross-sectional associations of $\mathrm{NO}_{2}$ with FVC and FEV1 [14] withstood more stringent adjustment for socioeconomic factors. The only SES-variable that improved the model fit was education. Education was independently and positively associated with lung function, and it slightly confounded the association of $\mathrm{NO}_{2}$ and lung function. We can only speculate about reasons why there was no evidence of an association of the other two SES-variables with lung function. It is possible that some manual professions might be beneficial to lung health (e.g., by being physically active or working outside), while other manual professions might expose workers to substances like dust and fumes and might therefore have negative effects. Unfortunately we did not have a variable for occupational exposure. As occupation is only a rough proxy of income, the effects of socio-economic factors on lung function may still have been underestimated. Unemployment rate at the community level might be influenced by factors going beyond the individual SES of the residents, e.g., by industrialization of the neighborhood [10].

From the perspective of causal inference and air quality regulation, it is essential to demonstrate the independence of adverse health effects of air pollution from potentially correlated health risk factors, including SES. The goal is to best possibly assess the causality of air pollution effects on health and well-being in order to justify investments into improved air quality. SES and poverty have been discussed for decades as important potential confounders or modifiers of air pollution-health associations $[11,12,21,22]$. This has stimulated our previous investigation into the association between air pollution and SES in different European cities [10], where we found the relationship of air pollution exposure and individual SES to strongly vary by city and country, as it had also been shown before [23]. Our results from geographically stratified analyses (Meta-Analyses, Supplement Table S1 and Figures S1 and S2) were quite homogeneous across study areas suggesting that these differences did not translate into differences in the air pollution-lung function association between study areas.

Our results add evidence towards a causal role of ambient air pollution in reducing lung function. It remains unclear whether $\mathrm{NO}_{2}$ health effects are clearly attributable to $\mathrm{NO}_{2}$ itself, or whether $\mathrm{NO}_{2}$ serves as a proxy for other polluting agents from combustion or traffic sources [24]. Whereas direct effects of $\mathrm{NO}_{2}$ on exacerbations of asthma have been established $[25,26]$, the causal understanding of the independent effect of long-term exposure to $\mathrm{NO}_{2}$ on cardio-respiratory morbidity including lung function remains poor in the light of the small number of studies investigating two- or even three-pollutant models [27]. 
From the perspective of health promotion it is not sufficient to consider air pollution effects in isolation [28]. The identification of factors that modify the susceptibility to air pollution is important. For example, we have previously shown that the respiratory function of obese persons may be more susceptible to inhaled pollutants from traffic exhaust [14] and may be less likely to recover after air quality improves [29]. These results point to the possibility that the benefits of improved air quality on respiratory health may be diminished by an uncontrolled obesity epidemic. Several studies previously demonstrated stronger adverse effects of air pollution on health in subjects with lower SES [11,12,21,22,28]. Brunt et al. [28] reported stronger $\mathrm{NO}_{2}, \mathrm{PM} 10$ and PM2.5 effects on respiratory disease mortality for the more deprived small geographic areas of Wales, whereas no associations were observed in the least deprived areas. Deprivation status of the geographic areas was itself strongly associated with respiratory disease mortality. This was in accordance with the general evidence for an almost 10 year difference in life-expectancy between the most and least deprived areas in the UK, which has so far been attributed largely to behaviors [30]. The results by [28] suggest that differences in environmental conditions may contribute to health differences by deprivation state. In the current study focusing on lung function as an endpoint, we did not observe statistically significant interactions between air pollution and the SES-variable education. If anything, there was a tendency for stronger air pollution effects in more educated persons irrespective of adjustment for lifestyle factors. But more educated persons still had better lung function. It remains unclear if this could be due to other lifestyle variables like physical activity and diet, which were not available in the current analysis. Future studies need to further clarify the complex interplay between SES, physical activity [31], additional lifestyle factors, and air pollution on lung function.

We observed independent associations of education with lung function. Those were larger than the effects of $\mathrm{NO}_{2}$ across the contrast observed in air quality. These SES-lung function associations may be partly explained by a correlation of low SES with occupational settings that promote respiratory diseases [32] and that are not well captured by an occupational variable merely differentiating between manual and non-manual work. In the current study the latter variable was not associated with lung function. The education-lung function association could also be mediated by behaviors that are themselves bad for lung health (e.g., poor nutrition, physical inactivity, obesity, smoking) [6,12]. As the positive association of SES with lung function was limited to education, this individual SES parameter seems to best capture mediators of lung function in our study.

Our study has several advantages. It covers a wide range of urban areas representing different regions of Western Europe. $\mathrm{NO}_{2}$ exposure was estimated with the same methodology for all centers, which makes our results comparable across studies and centers. The centers included cover a wide range of $\mathrm{NO}_{2}$ exposure, with estimated annual means ranging from $5.3 \mu \mathrm{g} / \mathrm{m}^{3}$ (Umea, Sweden) to $58.2 \mu \mathrm{g} / \mathrm{m}^{3}$ (Barcelona, Spain) (Figure 1). The protocols and study designs of the three studies were quite similar. However, the current study is cross-sectional by design and we can therefore not differentiate whether people with low lung function and respiratory problems are less likely to succeed professionally and thus live in more deprived areas or whether low educational achievements and jobs and poor residential conditions lead to poor lung function later in life. There may be several explanations for why we did not observe statistically significant effect modification of the $\mathrm{NO}_{2}$-lung function associations by the SES variable education. It may reflect limitations in statistical power or in the data available to classify participants' SES. For example, we only had educational level and occupation available for individual SES classification. This null result may also reflect the true absence of effect modification.

\section{Conclusions}

These results provide further evidence that the inverse association between traffic-related air pollution and lung function is not the result of confounding by SES. Consequently, it is likely that improvements in air quality would benefit lung health $[33,34]$ in the entire population and might even help to reduce inequalities in health. Health benefits of improved air quality have been shown 
by many studies, e.g., for Lausanne, Switzerland, with a reduction of $1 \%-2 \%$ in all-cause annual mortality attributable to a decrease in $\mathrm{NO}_{2}$ [35]. A health impact analysis for Barcelona estimated a beneficial effect of 3500 fewer deaths as a result of reducing the mean PM10 exposure $\left(50 \mu \mathrm{g} / \mathrm{m}^{3}\right)$ to the annual mean value recommended by the WHO $\left(20 \mu \mathrm{g} / \mathrm{m}^{3}\right)$ [36]. Beneficial effects of different scenarios for PM2.5 reduction were also shown for 26 European cities [37]. The large potential impact of policy efforts for clean air can also be seen in the US, where the success in reducing air pollution was estimated to have prevented 160,000 cases of premature mortality and 130,000 heart attacks between 1990 and 2010 [38]. This is strong support for the call to develop global evidence-based clean air standards [39]. Given the importance of the topic from a health-in-all-policy perspective, factors determining susceptibility to air pollution must be studied further.

Supplementary Materials: The following are available online at http://www.mdpi.com/1660-4601/16/11/1901/s1; Figure S1: Meta-analysis of the association of $\mathrm{NO}_{2}$ with FVC in the full sample, by study center and overall; Figure S2: Meta-analysis of the association of $\mathrm{NO}_{2}$ with FEV1 in the full sample, by study center and overall; Table S1: Sensitivity analyses.

Author Contributions: Conceptualization, B.J. and N.P.-H.; Data curation, D.K., B.G. and S.T.; Formal analysis, D.K.; Funding acquisition, J.M.A., J.H., D.J., N.K., N.L.M., J.S., B.J. and N.P.-H.; Investigation, B.G., K.d.H. and M.-Y.T.; Methodology, D.K. and C.S.; Project administration, B.J.; Supervision, B.J. and N.P.-H.; Visualization, D.K.; Writing—original draft, D.K. and N.P.-H.; Writing—review and editing, D.K., J.M.A., X.B., R.B., E.B., A.-E.C., B.F., E.F., B.G., J.H., K.d.H., D.J., N.K., B.L., A.M., N.L.M., A.d.N., C.S., V.S., M.S., J.S., S.T., M.-Y.T., R.V., B.J. and N.P.-H.

Funding: ESCAPE (FP7/2007-2011, Grant Nr.211250). EGEA is funded in part by PHRC-Paris, PHRC-Grenoble, ANR 05-SEST-020-02/05-9-97, ANR-06-CEBS, ANR-CES-2009, Région Nord Pas-de-Calais, Merck Sharp \& Dohme (MSD), +ANSES. This work was supported by the French Agency for Food, Environmental and Occupational Health \& Safety [Grand Nr.PNR-EST-12-166]. Grants: Convention INSERM-MSD; INSERM network of clinical research; INSERM network of public health research; INSERM program IDS; Association française de lutte contre la mucoviscidose (AFLM); Direction for clinical research Grenoble; Ministry of Environment; Ministry of Health; Direction of Labour; Ministry of Research; Comittee of Respiratory Diseases; Cohorts and collections (Ministry of Research/Inserm); MSD grant; Direction of Labor- National institute for public health surveillance; Ministry of Environment-Health and Environment program; Agency for Environment and Energy Management. Hospital program of clinical research - Grenoble; Hospital program of clinical research-Paris; French Agency of health and environmental safety; French Agency of health safety, environment and work; Global allergy and asthma European network (Ga2len); Medico-technology support at home (Agir à dom); French speaking society of pneumology; National Research Agency-Health environment, health-work program; National Research Agency-Biological collections for health program; Isere committee against respiratory diseases; National Research Agency - Contaminants, ecosystems, health; French Agency of health safety, environment and work; French society of Nutrition; National Research Agency - Public Health Research Program; National Research Agency - Public Health Research Program; Fonds de dotation respiratoire; Aviesan - ITMO Santé Publique - Financement cohorts. SAPALDIA Research support: The Swiss National Science Foundation (grants no 33CS30-177506/1, 33CS30-148470/1\&2, 33CSCO-134276/1, 33CSCO-108796, 324730_135673, 3247BO-104283, 3247BO-104288, 3247BO-104284, 3247-065896, 3100-059302, 3200-052720, 3200-042532, 4026-028099, PMPDP3_129021/1, PMPDP3_141671/1), the Federal Office for the Environment, the Federal Office of Public Health, the Federal Office of Roads and Transport, the canton's government of Aargau, Basel-Stadt, Basel-Land, Geneva, Luzern, Ticino, Valais, and Zürich, the Swiss Lung League, the canton's Lung League of Basel Stadt/ Basel Landschaft, Geneva, Ticino, Valais, Graubünden and Zurich, Stiftung ehemals Bündner Heilstätten, SUVA, Freiwillige Akademische Gesellschaft, UBS Wealth Foundation, Talecris Biotherapeutics GmbH, Abbott Diagnostics, Klinik Barmelweid, Hirslanden Klinik Aarau, European Commission 018996 (GABRIEL), Wellcome Trust WT 084703MA, Exposomics EC FP7 grant(Grant agreement No: 308610).

Acknowledgments: We thank all study members and staff involved in data collections in each cohort and also the respective funding bodies for ECRHS, EGEA, and SAPALDIA. ECRHS: The ECRHS data collected during the first follow-up and incorporated in this analysis would not have been available without the collaboration of the following individuals and their research teams at the time. ECRHS co-ordinating centre: P. Burney, D. Jarvis, S. Chinn, J. Knox (ECRHS II), C. Luczynskat, J. Potts. Steering Committee for ECRHS II: P. Burney, D. Jarvis, S. Chinn, J.M. Anto, I. Cerveri, R. deMarco, T. Gislason, J. Heinrich, C. Janson, N. Kunzli, B. Leynaert, F. Neukirch, T. Rochat, J. Schouten, J. Sunyer, C. Svanes, P. Vermeiret, M. Wjst. Principal Investigators and Senior Scientific Teams for ECRHS II:; Belgium: South Antwerp and Antwerp City (P. Vermeiret, J. Weyler, M. Van Sprundel, V. Nelen); France: Paris (F. Neukirch, B. Leynaert, R. Liard, M. Zureik), Grenoble (I. Pin, J. Ferran-Quentin); Germany: Erfurt (J. Heinrich, M. Wjst, C. Frye, I. Meyer); Italy: Turin (M. Bugiani, P. Piccioni, E. Caria, A. Carosso, E. Migliore, G. Castiglioni), Verona (R. de Marco, G. Verlato, E. Zanolin, S. Accordini, A. Poli, V. Lo Cascio, M. Ferrari), Pavia (A. Marinoni, S. Villani, M. Ponzio, F. Frigerio, M. Comelli, M. Grassi, I. Cerveri, A. Corsico); Spain: Barcelona (J.M. Anto, J. Sunyer, M. Kogevinas, J.P. Zock, X. Basagana, A. Jaen, F. Burgos), Huelva (J. Maldonado, A. Pereira, J.L. Sanchez), Albacete (J. Martinez-Moratalla Rovira, E. Almar), Galdakao (N. Muniozguren, I. Urritia), Oviedo (F. Payo); Sweden: Umea (E. Norrman, M. Soderberg, K. Franklin, B. Lundback, B. Forsberg, L. Nystrom); UK: Norwich 
(D. Jarvis, B. Harrison), Ipswich (D. Jarvis, R. Hall, D. Seaton); The excellent fieldwork by Gabriele Wölke and Matthias Birk is highly acknowledged. EGEA: Coordination: V Siroux (epidemiology, PI since 2013); F Demenais (genetics); I Pin (clinical aspects); R Nadif (biology); F Kauffmann (PI 1992-2012). Respiratory epidemiology: Inserm ex-U 700, Paris: M Korobaeff (Egea1), F Neukirch (Egea1); Inserm ex-U 707, Paris: I Annesi-Maesano (Egea1-2); Inserm ex-U 1018, Villejuif: F Kauffmann, MP Oryszczyn (Egea1-2); Inserm U 1168, Villejuif: N Le Moual, R Nadif, R Varraso; Inserm U 1209 Grenoble: V Siroux. Genetics: Inserm ex-U 393, Paris: J Feingold; Inserm U 946, Paris: E Bouzigon, F Demenais, MH Dizier; CNG, Evry: I Gut (now CNAG, Barcelona, Spain), M Lathrop (now Univ McGill, Montreal, Canada). Clinical centers: Grenoble: I Pin, C Pison; Lyon: D Ecochard (Egea1), F Gormand, Y Pacheco; Marseille: D Charpin (Egea1), D Vervloet (Egea1-2); Montpellier: J Bousquet; Paris Cochin: A Lockhart (Egea1), R Matran (now in Lille); Paris Necker: E Paty (Egea1-2), P Scheinmann (Egea1-2); Paris-Trousseau: A Grimfeld (Egea1-2), J Just. Data and quality management: Inserm ex-U155 (Egea1): J Hochez; Inserm U 1168, Villejuif: N Le Moual; Inserm ex-U780: C Ravault (Egea1-2); Inserm ex-U794: N Chateigner (Egea1-2); Grenoble: J Quentin (Egea1-2). SAPALDIA: Study directorate: NM Probst-Hensch (PI; e/g); D Stolz (p), C Schindler (s), N Künzli (e/exp). Scientific team: JC Barthélémy (c), W Berger (g), R Bettschart (p), A Bircher (a), C Brombach (n), PO Bridevaux (p), L Burdet (p), Felber Dietrich D (e), T Sigrist (p), U Frey (pd), MW Gerbase (p), D Gold (e), E de Groot (c), W Karrer (p), F Kronenberg (g), B Martin (pa), A Mehta (e), D Miedinger (o), M Pons (p), F Roche (c), T Rothe (p), P Schmid-Grendelmeyer (a), A Schmidt-Trucksäss (pa), J Schwartz (e), A Turk (p), A von Eckardstein (cc), E Zemp Stutz (e). Scientific team at coordinating centers: M Adam (e), I Aguilera (exp), A Beckmeyer-Borowko (e), S Brunner (s), D Carballo (c), S Caviezel (pa), I Curjuric (e), A Di Pascale (s), J Dratva (e), R Ducret (s), E Dupuis Lozeron (s), M Eeftens (exp), I Eze (e), E Fischer (g), M Foraster (e), M Germond (s), L Grize (s), S Hansen (e), A Hensel (s), M Imboden (g), A Ineichen (exp), A Jeong (g), D Keidel (s), A Kumar (g), N Maire (s), A Mehta (e), R Meier (exp), E Schaffner (s), T Schikowski (e), M Tsai (exp). (a) allergology, (c) cardiology, (cc) clinical chemistry, (e) epidemiology, (exp) exposure, (g) genetic and molecular biology, (m) meteorology, (n) nutrition, (o) occupational health, (p) pneumology, (pa) physical activity, (pd) pediatrics, (s) statistics The study could not have been done without the help of the study participants, technical and administrative support and the medical teams and field workers at the local study sites. Local fieldworkers: Aarau: S Brun, G Giger, M Sperisen, M Stahel, Basel: C Bürli, C Dahler, N Oertli, I Harreh, F Karrer, G Novicic, N Wyttenbacher, Davos: A Saner, P Senn, R Winzeler, Geneva: F Bonfils, B Blicharz, C Landolt, J Rochat, Lugano: S Boccia, E Gehrig, MT Mandia, G Solari, B Viscardi, Montana: AP Bieri, C Darioly, M Maire, Payerne: F Ding, P Danieli A Vonnez, Wald: D Bodmer, E Hochstrasser, R Kunz, C Meier, J Rakic, U Schafroth, A Walder. Administrative staff: N Bauer Ott, C Gabriel, R Gutknecht.

Conflicts of Interest: The authors declare no conflict of interest. The funders had no role in the design of the study; in the collection, analyses, or interpretation of data; in the writing of the manuscript, or in the decision to publish the results.

\section{References}

1. WHO. Ambient Air Pollution: A Global Assessment of Exposure and Burden of Disease; World Health Organization: Geneva, Switzerland, 2016.

2. Cohen, A.J.; Brauer, M.; Burnett, R.; Anderson, H.R.; Frostad, J.; Estep, K.; Balakrishnan, K.; Brunekreef, B.; Dandona, L.; Dandona, R.; et al. Estimates and 25-year trends of the global burden of disease attributable to ambient air pollution: An analysis of data from the Global Burden of Diseases Study 2015. Lancet 2017, 389, 1907-1918. [PubMed]

3. EEA. Air Quality in Europe-2016 Report. European Environment Agency Report No 28/2016; Publications Office of the European Union: Luxembourg, 2016.

4. Wheeler, B.W.; Ben-Shlomo, Y. Environmental equity, air quality, socioeconomic status, and respiratory health: A linkage analysis of routine data from the Health Survey for England. J. Epidemiol. Community Health 2005, 59, 948-954. [CrossRef] [PubMed]

5. O’Neill, M.S.; Jerrett, M.; Kawachi, I.; Levy, J.I.; Cohen, A.J.; Gouveia, N.; Wilkinson, P.; Fletcher, T.; Cifuentes, L.; Schwartz, J.; et al. Health, wealth, and air pollution: Advancing theory and methods. Environ. Health Perspect. 2003, 111, 1861-1870. [CrossRef]

6. Hegewald, M.J.; Crapo, R.O. Socioeconomic status and lung function. Chest 2007, 132, 1608-1614. [CrossRef] [PubMed]

7. McFadden, E.; Luben, R.; Wareham, N.; Bingham, S.; Khaw, K.T. How far can we explain the social class differential in respiratory function? A cross-sectional population study of 21,991 men and women from EPIC-Norfolk. Eur. J. Epidemiol. 2009, 24, 193-201. [CrossRef]

8. Schikowski, T.; Sugiri, D.; Reimann, V.; Pesch, B.; Ranft, U.; Krämer, U. Contribution of smoking and air pollution exposure in urban areas to social differences in respiratory health. BMC Public Health 2008, 8, 179. [CrossRef] [PubMed] 
9. Braveman, P.A.; Cubbin, C.; Egerter, S.; Chideya, S.; Marchi, K.S.; Metzler, M.; Posner, S. Socioeconomic status in health research: One size does not fit all. JAMA 2005, 294, 2879-2888. [CrossRef] [PubMed]

10. Temam, S.; Burte, E.; Adam, M.; Antó, J.M.; Basagaña, X.; Bousquet, J.; Carsin, A.E.; Galobardes, B.; Keidel, D.; Künzli, N. Socioeconomic position and outdoor nitrogen dioxide $\left(\mathrm{NO}_{2}\right)$ exposure in Western Europe: A multi-city analysis. Environ. Int. 2017, 101, 117-124. [CrossRef]

11. Chi, G.C.; Hajat, A.; Bird, C.E.; Cullen, M.R.; Griffin, B.A.; Miller, K.A.; Shih, R.A.; Stefanick, M.L.; Vedal, S.; Whitsel, E.A.; et al. Individual and Neighborhood Socioeconomic Status and the Association between Air Pollution and Cardiovascular Disease. Environ Health Perspect. 2016, 124, 1840-1847. [CrossRef]

12. Laurent, O.; Bard, D.; Filleul, L.; Segala, C. Effect of socioeconomic status on the relationship between atmospheric pollution and mortality. J. Epidemiol. Community Health 2007, 61, 665-675. [CrossRef] [PubMed]

13. Humphrey, J.L.; Lindstrom, M.; Barton, K.E.; Shrestha, P.M.; Carlton, E.J.; Adgate, J.L.; Miller, S.L.; Root, E.D. Social and Environmental Neighborhood Typologies and Lung Function in a Low-Income, Urban. Population. Int. J. Environ. Res. Public Health 2019, 16, 1133. [CrossRef] [PubMed]

14. Adam, M.; Schikowski, T.; Carsin, A.E.; Cai, Y.; Jacquemin, B.; Sanchez, M.; Vierkötter, A.; Marcon, A.; Keidel, D.; Sugiri, D.; et al. Adult lung function and long-term air pollution exposure. ESCAPE: A multicentre cohort study and meta-analysis. Eur. Respir. J. 2015, 45, 38-50. [CrossRef]

15. Jarvis, D. The European Community Respiratory Health Survey II. Eur. Respir. J. 2002, 20, 1071-1079.

16. Ackermann-Liebrich, U.; Kuna-Dibbert, B.; Probst-Hensch, N.M.; Schindler, C.; Dietrich, D.F.; Stutz, E.Z.; Bayer-Oglesby, L.; Baum, F.; Brändli, O.; Brutsche, M.; et al. Follow-up of the Swiss Cohort Study on Air Pollution and Lung Diseases in Adults (SAPALDIA 2) 1991-2003: Methods and characterization of participants. Soz Praventivmed. 2005, 50, 245-263. [CrossRef] [PubMed]

17. Siroux, V.; Boudier, A.; Bousquet, J.; Bresson, J.L.; Cracowski, J.L.; Ferran, J.; Gormand, F.; Just, J.; Le Moual, N.; Morange, S. Phenotypic determinants of uncontrolled asthma. J. Allergy Clin. Immunol. 2009, 124, 681-687. [CrossRef]

18. Beelen, R.; Hoek, G.; Vienneau, D.; Eeftens, M.; Dimakopoulou, K.; Pedeli, X.; Tsai, M.Y.; Künzli, N.; Schikowski, T.; Marcon, A.; et al. Development of $\mathrm{NO}_{2}$ and NOx land use regression models for estimating air pollution exposure in 36 study areas in Europe-The ESCAPE project. Atmos. Environ. 2013, 72, 10-23. [CrossRef]

19. ATC. Standardization of Spirometry, 1994 Update. American Thoracic Society. Am. J. Respir. Crit. Care Med. 1995, 152, 1107-1136. [CrossRef]

20. ISCO88. International Standard Classification of Occupations; Revised Edition ISCO-88; International Labour Office: Geneva, Switzerland, 1991.

21. Deguen, S.; Zmirou-Navier, D. Social inequalities resulting from health risks related to ambient air quality-A European review. Eur. J. Public Health 2010, 20, 27-35. [CrossRef]

22. Forastiere, F.; Stafoggia, M.; Tasco, C.; Picciotto, S.; Agabiti, N.; Cesaroni, G.; Perucci, C.A. Socioeconomic status, particulate air pollution, and daily mortality: Differential exposure or differential susceptibility. Am. J. Ind. Med. 2007, 50, 208-216. [CrossRef]

23. Padilla, C.M.; Kihal-Talantikite, W.; Vieira, V.M.; Rossello, P.; Le Nir, G.; Zmirou-Navier, D.; Deguen, S. Air quality and social deprivation in four French metropolitan areas-A localized spatio-temporal environmental inequality analysis. Environ. Res. 2014, 134, 315-324. [CrossRef]

24. Kutlar Joss, M.; Dyntar, D.; Rapp, R. Gesundheitliche Wirkungen der $\mathrm{NO}_{2}$-Belastung auf den Menschen: Synthese der Neueren Literatur auf Grundlage des WHO-REVIHAAP Berichts; Swiss Tropical and Public Health Institute: Basel, Switzerland, 2015.

25. EPA. Integrated Science Assessment for Oxides of Nitrogen-Health Criteria; USA Environmental Protection Agency: Research Triangle Park, NC, USA, 2016.

26. Muñoz, X.; Barreiro, E.; Bustamante, V.; Lopez-Campos, J.L.; González-Barcala, F.J.; Cruz, M.J. Diesel exhausts particles: Their role in increasing the incidence of asthma. Reviewing the evidence of a causal link. Sci. Total Environ. 2019, 652, 1129-1138. [CrossRef]

27. WHO. Health Risks of Air Pollution in Europe-HRAPIE Project; World Health Organization: Geneva, Switzerland, 2013.

28. Brunt, H.; Barnes, J.; Jones, S.J.; Longhurst, J.W.S.; Scally, G.; Hayes, E. Air pollution, deprivation and health: Understanding relationships to add value to local air quality management policy and practice in Wales, UK. J. Public Health (Oxf.) 2016, 39, 485-497. [CrossRef] 
29. Schikowski, T.; Schaffner, E.; Meier, F.; Phuleria, H.C.; Vierkötter, A.; Schindler, C.; Kriemler, S.; Zemp, E.; Krämer, U.; Bridevaux, P.O.; et al. Improved air quality and attenuated lung function decline: Modification by obesity in the SAPALDIA cohort. Environ. Health Perspect. 2013, 121, 1034-1039. [CrossRef] [PubMed]

30. Marmot, M.; Bell, R. Fair society, healthy lives. Public Health 2012, 126 (Suppl. 1), S4-S10. [CrossRef] [PubMed]

31. Fuertes, E.; Markevych, I.; Jarvis, D.; Vienneau, D.; de Hoogh, K.; Antó, J.M.; Bowatte, G.; Bono, R.; Corsico, A.G.; Emtner, M.; et al. Residential air pollution does not modify the positive association between physical activity and lung function in current smokers in the ECRHS study. Environ. Int. 2018, 120, 364-372. [CrossRef]

32. ILO. ILO List of Occupational Diseases; International Labour Organization: Geneva, Switzerland, 2010.

33. Downs, S.H.; Schindler, C.; Liu, L.J.S.; Keidel, D.; Bayer-Oglesby, L.; Brutsche, M.H.; Gerbase, M.W.; Keller, R.; Künzli, N.; Leuenberger, P.; et al. Reduced exposure to PM10 and attenuated age-related decline in lung function. N. Engl. J. Med. 2007, 357, 2338-2347. [CrossRef]

34. Schindler, C.; Keidel, D.; Gerbase, M.W.; Zemp, E.; Bettschart, R.; Brandli, O.; Brutsche, M.H.; Burdet, L.; Karrer, W.; Knopfli, B.; et al. Improvements in PM10 exposure and reduced rates of respiratory symptoms in a cohort of Swiss adults (SAPALDIA). Am. J. Respir. Crit. Care Med. 2009, 179, 579-587. [CrossRef]

35. Castro, A.; Kunzli, N.; Gotschi, T. Health benefits of a reduction of $\mathrm{PM} 10$ and $\mathrm{NO}_{2}$ exposure after implementing a clean air plan in the Agglomeration Lausanne-Morges. Int. J. Hyg. Environ. Health 2017, 220, 829-839. [CrossRef] [PubMed]

36. Perez, L.; Sunyer, J.; Kunzli, N. Estimating the health and economic benefits associated with reducing air pollution in the Barcelona metropolitan area (Spain). Gac. Sanit. 2009, 23, 287-294. [CrossRef] [PubMed]

37. Ballester, F.; Medina, S.; Boldo, E.; Goodman, P.; Neuberger, M.; Iñiguez, C.; Künzli, N. Reducing ambient levels of fine particulates could substantially improve health: A mortality impact assessment for 26 European cities. J. Epidemiol. Community Health 2008, 62, 98-105. [CrossRef]

38. EPA. The Benefits and Costs of the Clean Air Act from 1990 to 2020; Final Report-Rev. A; USA Environmental Protection Agency, Office of Air and Radiation: Washington, DC, USA, 2011.

39. Kutlar Joss, M.; Eeftens, M.; Gintowt, E.; Kappeler, R.; Künzli, N. Time to harmonize national ambient air quality standards. Int. J. Public Health 2017, 62, 453-462. [CrossRef] [PubMed]

(C) 2019 by the authors. Licensee MDPI, Basel, Switzerland. This article is an open access article distributed under the terms and conditions of the Creative Commons Attribution (CC BY) license (http://creativecommons.org/licenses/by/4.0/). 